Journal of Advanced Research in Fluid Mechanics and Thermal Sciences

Journal homepage: www.akademiabaru.com/arfmts.html ISSN: 2289-7879

\title{
Performance Evaluation of Axial Flow Wind Turbine Integrated with The Condenser
}

Mechanical Engineering Department, Universitas Sebelas Maret, Surakarta, Indonesia

\section{ARTICLE INFO ABSTRACT}

Article history:

Received 29 May 2020

Received in revised form 15 September 2020

Accepted 20 September 2020

Available online 26 October 2020

\begin{abstract}
This study investigated the application of an axial flow wind turbine integrated with a condenser. The exhaust air from condenser was used to drive the wind turbine by a ducted turbine system. There were two parameters varied in this work: the blade number and the blade pitch angle. The blade number used was two blades, five blades, and ten blades, while the blade pitch angles were $5^{\circ}, 10^{\circ}, 15^{\circ}, 20^{\circ}, 30^{\circ}$, and $45^{\circ}$. The diameter of the wind turbine was $495 \mathrm{~mm}$. The model of the condenser had a fan diameter of $600 \mathrm{~mm}$ and the range of the average air velocity of $2.01 \mathrm{~m} / \mathrm{s}-7.86 \mathrm{~m} / \mathrm{s}$. The maximum mechanical power was $10.72 \mathrm{~W}$ for air velocity of $7.86 \mathrm{~m} / \mathrm{s}$. The maximum power coefficient recorded was 0.38 for the tip speed ratio of 1.3 on the blade number of five blades and a pitch angle of $10^{\circ}$. The maximum exhaust air energy recovery was $13.64 \%$ of the power consumption of the condenser fan.
\end{abstract}

Keywords:

Exhaust Air; Energy Recovery;

Condenser; Axial Flow Wind Turbine;

Airfoil

Copyright @ 2020 PENERBIT AKADEMIA BARU - All rights reserved

\section{Introduction}

It is unquestionable that world energy demand will increase dramatically in the future. By 2050, it is forecast to increase to $1000 \mathrm{EJ}(E \mathrm{EJ}=1018 \mathrm{~J})$ [1-3]. If this demand is mainly from fossil fuels, this, of course, will bring harmful impacts on the world's climate due to the greenhouse gasses. Therefore, renewable energy has an important role in this path due to its environmentally-friendly sources and the potential for cost reduction [4]. There have been many works in the area of renewable energy in which wind turbine becomes the second biggest source of energy and the fastest growing renewable source in the world [5].

The principle of the wind turbine is to convert energy from the wind to electrical power. There are two types of wind turbine: vertical axis wind turbine (VAWT) and horizontal axis wind turbine (HAWT) [6]. HAWTs are the most favorite turbine machine and have better performance in extracting

\footnotetext{
* Corresponding author.

E-mail address: msbudis@yahoo.co.id

https://doi.org/10.37934/arfmts.76.3.8591
} 
wind power than VAWTs, though, in certain conditions, VAWTs is more preferable because it has advantages such as easy maintenance, less visual impact and low noise emission [7].

Generally, the wind turbine is used in the area that has high and consistent wind speed such as Eastern Islands which may have wind speed more than $5 \mathrm{~m} / \mathrm{s}$. However, in Indonesia, the use of a wind turbine is not efficient since the wind speed is low and inconsistent. Santoso et al., [8] develop a cross-flow wind turbine integrated with a cooling tower. A cross-flow wind turbine is a new design of VAWT that is fast and suitable for low wind speed. This work aimed to understand the influence of guide vane in the wind turbine integrated with a cooling tower by varying the position and the angle of attack of the guide vane. It is showed that the installation of guide vane at the right position indicated a significant increase in the coefficient of power (Cp) compared to wind turbine integrated with a cooling tower without guide vane. Chong et al., [9] develop two VAWTs in cross-wind orientation integrated with a cooling tower. The guide vane was placed in between the discharged air outlet and wind turbine. The results showed that this system could be used for building lighting in an urban building which can reduce the consumption of fossil fuels.

Chong et al., [10] conducted a study on the utilization of wind energy produced by the cooling tower. It is because the cooling tower can produce a constant air velocity and greater than the natural wind speed. A vertical axis wind turbine (VAWT) is integrated with a cooling tower outlet with a wind speed of $8 \mathrm{~m} / \mathrm{s}$. As a result, VAWT is expected to recover $13 \%$ of cooling tower power consumption [10]. Asl et al., [11] researched the performance of axial flow wind turbines placed on the convergingdiverging duct. The study was to determine the effect of blades number and slope angles using the converging-diverging duct on the performance of axial flow wind turbines. As a result, the axial flow wind turbine works optimally on two blades number, and the slope angle is $75^{\circ}$, and the use of converging-diverging duct increases turbine rotational speed $240.06 \%$ [11].

In this work, the axial-flow wind turbine, which is a new design of HAWT, was developed and integrated with the condenser, instead of the cooling tower. The choice of an axial turbine integrated with the condenser is all the area of exhaust air to drive the wind turbine. The blade numbers and the blade pitch angles were varied to obtain the maximum $\mathrm{Cp}$ and the maximum exhaust air recovery. The reason underlying the variation of the blades number and the blade pitch angles is because the addition of blades number can increase the torque and mechanical power followed by decreasing the value of cut-in speed and increasing starting torque from axial-flow wind turbine, while the change of blade pitch angle will affect the magnitude of drag and lift force generated by the blade so that the greater blade pitch angle, the lower resulting lift force, but the drag force will be even bigger [12-14].

\section{Research Methods}

Turbine mechanical power is the result of the turbine's ability to absorb the energy contained in the airflow. Energy in the airflow will rotate the turbine so that the rotor can produce torsions and has a rotating speed. The amount of turbine mechanical power is expressed by Eq. (1)

$$
P_{t}=\frac{2 \pi N \tau}{60}(\text { Watt })
$$

Where $\mathrm{N}$ is the turbine rotational speed $(\mathrm{rpm})$, and $\mathrm{\tau}$ is the torque that can be produced by the turbine $(\mathrm{Nm})$. The energy contained in the airflow can be determined by Eq. (2)

$$
P_{0}=1 / 2 \rho V^{3} A \text { (Watt) }
$$


The ratio between the mechanical power of the turbine and the energy contained in the airflow is called the power coefficient (CP). The amount of $\mathrm{CP}$ is expressed in the Eq. (3)

$C_{P}=\frac{P_{t}}{P_{0}}$

A condenser model was fabricated to represent an exhaust air system. The model has an axial flow fan with $600 \mathrm{~mm}$ diameter and powered by 780 Watt rated motor. The inlet, throat and outlet diameters of the duct are $770 \mathrm{~mm}, 516 \mathrm{~mm}$ and $667 \mathrm{~mm}$, respectively. The place for installing impellers is exactly the throat and the high from surface of condenser is $700 \mathrm{~mm}$. The research scheme can be seen in Figure 1. Variations carried out in this study are changing the blades number and blade pitch angle. In the present experiment blades used were NACA 6409. The scheme of changing the blades number and blade pitch angle can be seen in Figure 2 and Figure 3 . The experiment was carried out using variations in wind speed $2.01 \mathrm{~m} / \mathrm{s}, 2.52 \mathrm{~m} / \mathrm{s}, 2.96 \mathrm{~m} / \mathrm{s}, 3.51 \mathrm{~m} / \mathrm{s}$, $4.02 \mathrm{~m} / \mathrm{s}, 4.98 \mathrm{~m} / \mathrm{s}, 5.97 \mathrm{~m} / \mathrm{s}, 6.98 \mathrm{~m} / \mathrm{s}$, and $7.86 \mathrm{~m} / \mathrm{s}$. Experiments are used to find the shaft torque value, turbine mechanical power, power coefficient (CP), and TSR.

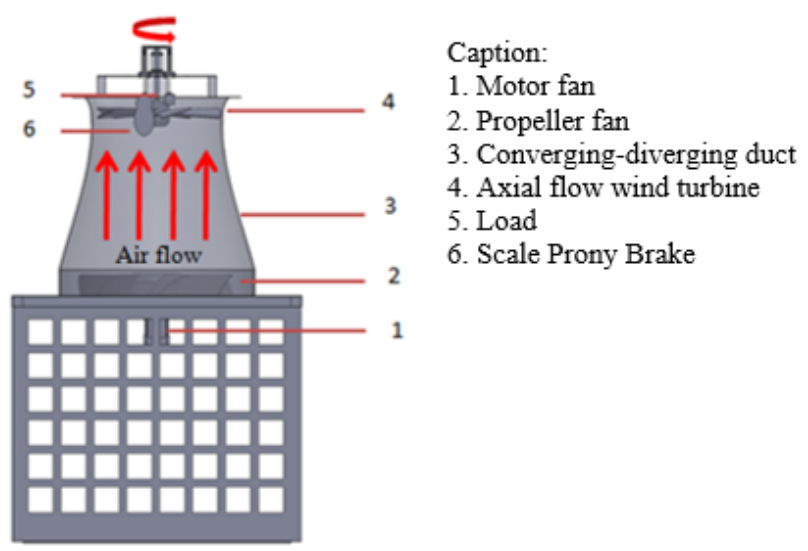

Fig. 1. Schematic of the experiment apparatus

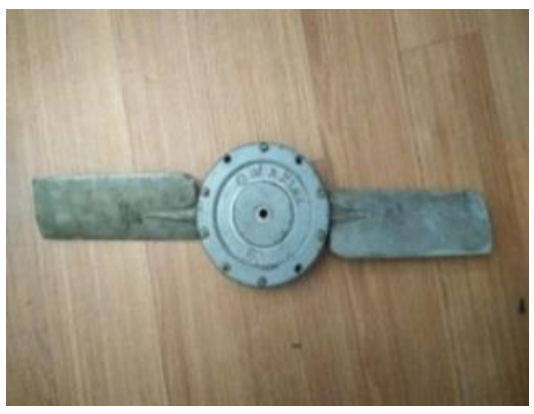

(a)

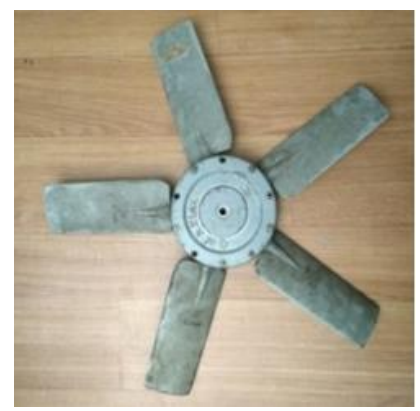

(b)

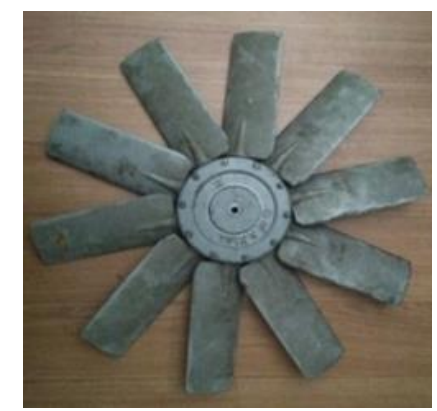

(c)

Fig. 2. Schematic of the blade number, (a) two blades (b) five blades (c) ten blades

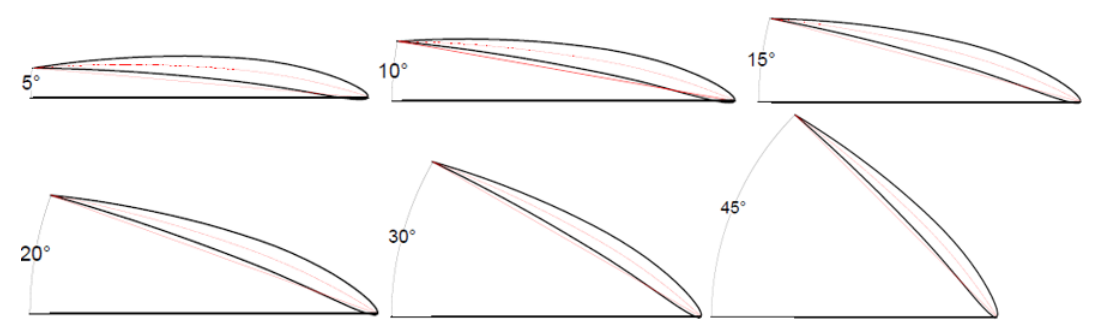

Fig. 3. Schematic of the blade pitch angle 


\section{Result}

The results of the power coefficient are provided in Figure 4. The power coefficient was tested for each variation the blade pitch angle and of wind speed. The power coefficient is below 0.5 at $45^{\circ} \mathrm{h}$ pitch angles. Note that the pitch angle is the angle between the circumference line and the blade chord shown in Figure 3. Figure 4(a) shows a graph of the relationship between CP and TSR in the tilt angle variation with the two blades number. The highest $C P$ value is obtained when the blade angle is set at $5^{\circ}$. The resulting CP value was 0.18 at a TSR value of 2.2. Increasing the angle of the blade causes the CP and TSR values to decrease. The decrease in CP value is due to the mechanical power generated by the wind turbine, which decreases with increasing blade angle. Meanwhile, the decrease in TSR value is caused by the turbine lift force, which is getting lower as the increasing of the turbine blade pitch angle. Turbine with a blade pitch angle of $5^{\circ}$, the $\mathrm{CP}$ value increases with increasing TSR value, then it will decrease when it has reached the optimum value at a certain TSR. It is due to the increasing TSR value; the air velocity used to drive the turbine is also increasing.

Figure 4(b) shows the relationship between CP and TSR produced by axial flow wind turbines with the five blades number. The maximum CP with the 5 blades number was found at TSR 1.1 and $10^{\circ}$ pitch angle, which is 0.38 . An increase in the blade pitch angle more $10^{\circ}$ causes a decrease in the value of CP and TSR, because of the turbine's torque and mechanical power decrease. Figure 4(c) shows that the axial flow wind turbine with the number of ten blades has the highest CP value of 0.3 on the TSR value of 0.9 . The blade pitch angle of $15^{\circ}$ produced the best $C P$ value compared to other the blade pitch angles of $5^{\circ}, 10^{\circ}, 15^{\circ}, 20^{\circ}, 30^{\circ}$, and $45^{\circ}$, respectively.

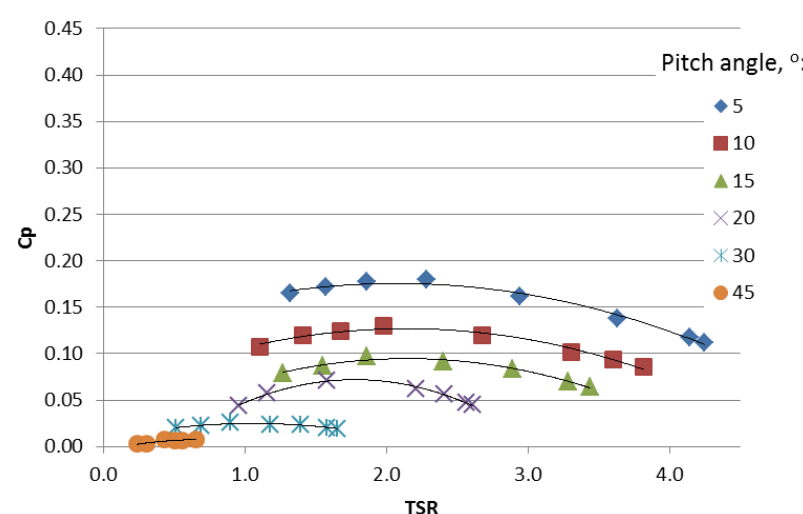

(a)

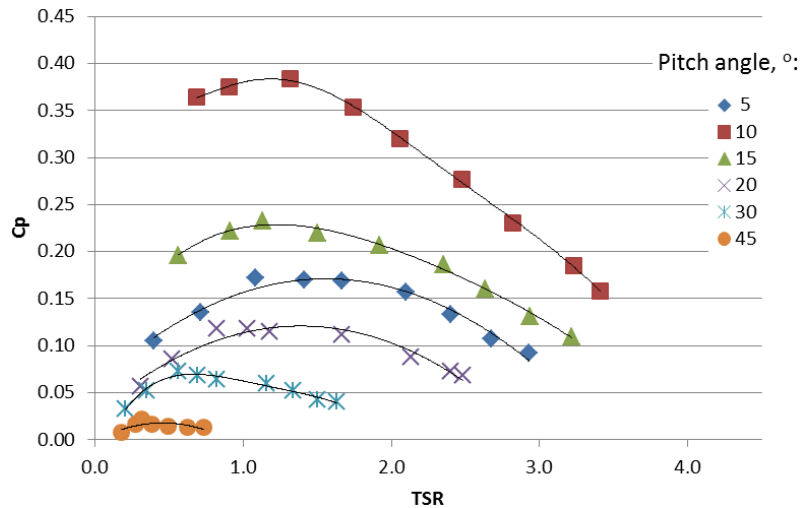

(b)

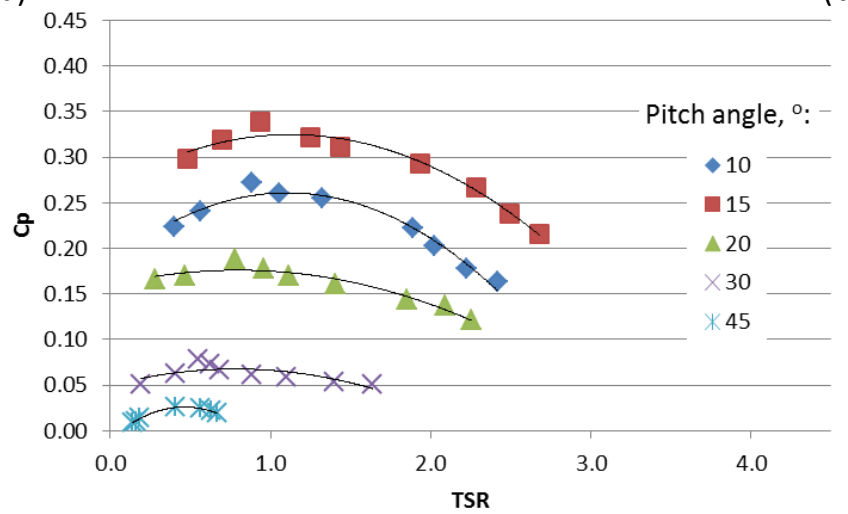

(c)

Fig. 4. Power coefficient in terms tip speed ratio for (a) two blades (b) five blades (c) ten blades 
The graph of CP and TSR in each number and the optimum blade angle can be seen in Figure 5 . The largest CP value is generated by turbines with the five blades number at the blade pitch angle of $10^{\circ}$ and followed ten blades number at blade pitch angle $15^{\circ}$. The turbine with two blades number at blade pitch angle $5^{\circ}$ produces the smallest CP value. The optimum value of CP is 0.38 at TSR of 1.3, 0.3 at TSR of 0.9 , and 0.18 at TSR of 2.2.

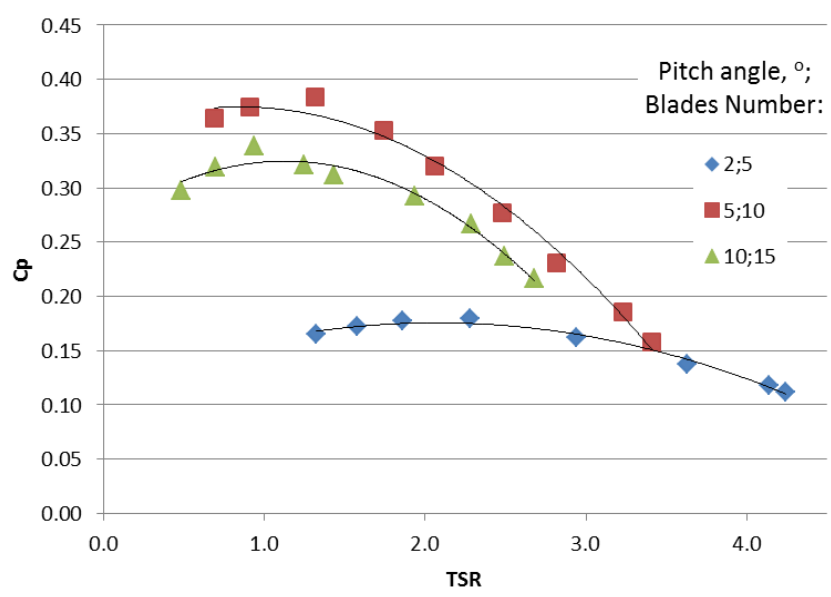

Fig. 5. Power coefficient with various pitch angle and blades number relative to the tip speed ratio

Figure 6 shows the mechanical power of a variation of the blades number relative to pitch angles. The maximum mechanical power is produced from pitch angles of $5^{\circ}, 10^{\circ}$, and $15^{\circ}$ for the blades number 2, 5, and 10, respectively. The biggest mechanical power in blades number of two, five, and ten are 5.54 Watts, 7.81 Watts, and 10.71 Watts, respectively. The blades number more used increased mechanical power because the torque produced greater than the torque from blades number slightly. The addition of blades number is related to the extent of the blade stroke on air. The greater blades number will provide enough blade area to transfer wind energy. As a result, more turbine blades, torque, and mechanical power produced will increase [13]. However, the addition blades number will reduce rotational speed produced by the axial flow wind turbine. Highest rotational speed in the turbine with a blades number two, five and ten are respectively $814 \mathrm{rpm}, 655$ $\mathrm{rpm}$, and $514 \mathrm{rpm}$. This decrease is caused by the channel throat section getting filled. It causes a blockage effect that will increase the pressure on the front of the rotor. Therefore, the rotational speed produced by the turbine will decrease further. This decrease in rotational speed ranges from 10-12.5\% in each addition of a blade. More blades number, lift force produced will increase as a result of an increase in blade area. So, the total lift force and torque produced will increase. However, lift force on each blade and rotational speed will decrease with an increasing blades number [10]. 


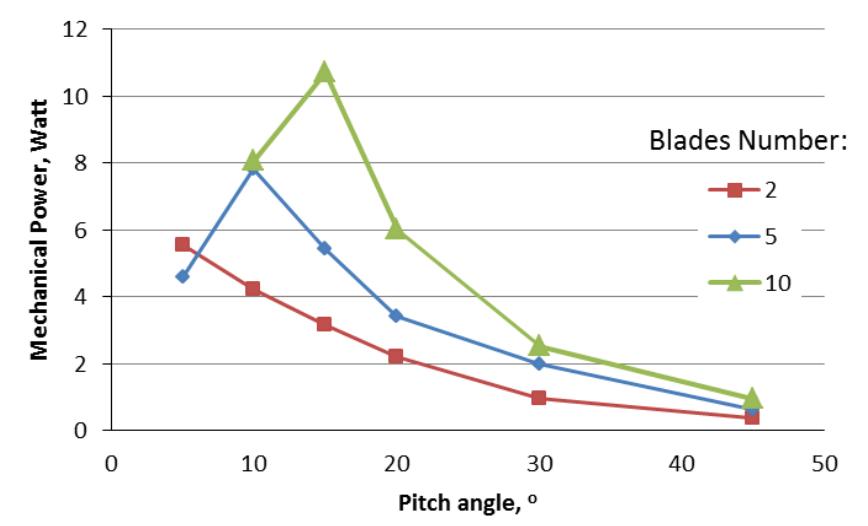

Fig. 6. The mechanical power of a various blades number relative to the pitch angle

\section{Discussion and Conclusion}

More blades number, optimum CP value is at lower TSR. It indicates that the value of starting torque is getting bigger. Increasing the value of starting torque causes wind turbine to rotate at lower wind speeds so that it can produce energy electricity early. As a result, an increasing blades number will reduce the cut-in speed value of axial flow wind turbine [15]. Axial flow wind turbines with ten blades number have lower CP values than wind turbines with five blades number. It was due to the blockage effect on ten blades number wind turbines which causes the rotation speed smaller about $27 \%$ than a turbine with five blades number. The decreasing in rotational speed causes a decrease in mechanical power produced by the axial flow wind turbine [12]. CP is a ratio between the mechanical power of a turbine and mechanical power contained in the airflow. The higher wind speed causes the greater mechanical power of the turbine produced, so mechanical power contained in airflow also increases. Increased power contained in airflow is greater when compared to the increase in mechanical power absorbed by wind turbines. It causes that the CP value is not at the highest TSR value.

The biggest mechanical power produced in each blades number has an optimum blade pitch angle. For 2,5 , and 10 blades number is blade pitch angle $5^{\circ}, 10^{\circ}$, and $15^{\circ}$, respectively. The blade pitch angle will affect the frontal area of blade collided with airflow. The greater blade pitch angle, the smaller frontal area of the blade, so that the turbine blade becomes more parallel with the direction of the turbine driving airflow. Increasing blade pitch angle will cause the angle of attack between blades with airflow to be greater. The larger attack angle causes a stalling effect on a turbine blade, so the coefficient of its tangential force (CT) decreases. Decreasing the CT value causes tangential force in blade also decrease; the effect of the lift force used to move blade is also smaller [12].

After conducting research and processing data, it can be concluded that

i. The axial flow wind turbine with five blades number and a pitch angle of $10^{\circ}$ produces the largest CP, which is 0.38 at a TSR value of 1.3 .

ii. The largest mechanical power produces at a pitch angle of $5^{\circ}, 10^{\circ}$, and $15^{\circ}$. The axial flow wind turbine with ten blades number produces the largest mechanical power at a pitch angle of $15^{\circ}$, and 10.7 Watt.

\section{Acknowledgment}

This work was supported by DP2M DIKTI (Directorate of Research and Public Service of Directorate General of Higher Education) Ministry of Research, Technology and Higher Education Indonesia 
through the grant of Applaied Research Scheme (Skim Penelitian Terapan) 2019 with contract number 718/UN27.21/PN/2019. The authors appreciate G. P. Picaso for their experimental cooperation.

\section{References}

[1] Moriarty, Patrick, and Damon Honnery. "What is the global potential for renewable energy?." Renewable and Sustainable Energy Reviews 16, no. 1 (2012): 244-252.

https://doi.org/10.1016/i.rser.2011.07.151

[2] Schiffer, Hans-Wilhelm. "WEC energy policy scenarios to 2050." Energy Policy 36, no. 7 (2008): 2464-2470. https://doi.org/10.1016/i.enpol.2008.02.045

[3] Riahi, Keywan, Arnulf Grübler, and Nebojsa Nakicenovic. "Scenarios of long-term socio-economic and environmental development under climate stabilization." Technological Forecasting and Social Change 74, no. 7 (2007): 887-935.

https://doi.org/10.1016/j.techfore.2006.05.026

[4] Dragomirescu, A. "Performance assessment of a small wind turbine with crossflow runner by numerical simulations." Renewable Energy 36, no. 3 (2011): 957-965.

https://doi.org/10.1016/j.renene.2010.07.028

[5] Kalantar, M. "Dynamic behavior of a stand-alone hybrid power generation system of wind turbine, microturbine, solar array and battery storage." Applied Energy 87, no. 10 (2010): 3051-3064.

https://doi.org/10.1016/i.apenergy.2010.02.019

[6] Chong, W. T., A. Fazlizan, S. C. Poh, K. C. Pan, W. P. Hew, and F. B. Hsiao. "The design, simulation and testing of an urban vertical axis wind turbine with the omni-direction-guide-vane." Applied Energy 112 (2013): 601-609.

https://doi.org/10.1016/i.apenergy.2012.12.064

[7] Chong, Wen-Tong, Wan Khairul Muzammil, Kok-Hoe Wong, Chin-Tsan Wang, Mohammed Gwani, Yung-Jeh Chu, and Sin-Chew Poh. "Cross axis wind turbine: Pushing the limit of wind turbine technology with complementary design." Applied Energy 207 (2017): 78-95.

https://doi.org/10.1016/i.apenergy.2017.06.099

[8] Santoso, Budi, and Dominicus Danardono Dwi Prija Tjahjana. "The Influence of Guide Vane to the Performance of Cross-Flow Wind Turbine on Waste Energy Harvesting System." In MATEC Web of Conferences, vol. 159, p. 02014. EDP Sciences, 2018. https://doi.org/10.1051/matecconf/201815902014

[9] Chong, Wen Tong, S. Y. Yip, A. Fazlizan, Sin Chew Poh, Wooi Ping Hew, Ee Peng Tan, and T. S. Lim. "Design of an exhaust air energy recovery wind turbine generator for energy conservation in commercial buildings." Renewable Energy 67 (2014): 252-256.

https://doi.org/10.1016/j.renene.2013.11.028

[10] Chong, W. T., S. C. Poh, A. Fazlizan, S. Y. Yip, C. K. Chang, and W. P. Hew. "Early development of an energy recovery wind turbine generator for exhaust air system." Applied Energy 112 (2013): 568-575.

https://doi.org/10.1016/j.apenergy.2013.01.042

[11] Asl, Hamid Ahmadi, Reza Kamali Monfared, and Manouchehr Rad. "Experimental investigation of blade number and design effects for a ducted wind turbine." Renewable Energy 105 (2017): 334-343. https://doi.org/10.1016/i.renene.2016.12.078

[12] Ridway Balaka, Aditya Rachman, and Jenny Delly. "Blade number effect for a horizontal axis river current turbine at a low velocity condition utilizing a parametric study with mathematical model of blade element momentum." Journal of Clean Energy Technologies 2, no. 1 (2014): 1-5. https://doi.org/10.7763/JOCET.2014.V2.79

[13] Wang, Sheng-Huan, and Shih-Hsiung Chen. "Blade number effect for a ducted wind turbine." Journal of Mechanical Science and Technology 22, no. 10 (2008): 1984-1992.

https://doi.org/10.1007/s12206-008-0743-8

[14] Sudhamshu, A. R., Manik Chandra Pandey, Nivedh Sunil, N. S. Satish, Vivek Mugundhan, and Ratna Kishore Velamati. "Numerical study of effect of pitch angle on performance characteristics of a HAWT." Engineering Science and Technology, an International Journal 19, no. 1 (2016): 632-641.

https://doi.org/10.1016/j.jestch.2015.09.010

[15] Bansal, A., D. A. Howey, and A. S. Holmes. "CM-scale air turbine and generator for energy harvesting from lowspeed flows." In TRANSDUCERS 2009-2009 International Solid-State Sensors, Actuators and Microsystems Conference, pp. 529-532. IEEE, 2009.

https://doi.org/10.1109/SENSOR.2009.5285378 